\title{
A Rudimentary Framework for Improving Access to Public Health using ICT
}

\author{
Kollapalli Ramesh Babu, A B Sagar, Ashish Kataria
}

\begin{abstract}
The growth of public health in India has been moderate due to low public expenditure on health, very few public health institutes and inadequate national standards for public health education. As per to the Global Burden of Disease Study (GBD) published in the medical journal, The Lancet, India has a depressing $154^{\text {th }}$ place among 195 countries on the healthcare index. India has population of 1.21 billion population and occupies the second position as the most populous country in the world. India has almost 13.1 per cent of child population aged 0-6 years (Census 2011). Mortality among infants and under-5 children is also a primary concern. In India the number of Under-5 mortality rate and infant mortality rates are very high. They are as much as 49 (Under-5 mortality rate) and 42 (infant mortality rates). The proposed framework is for improving the health of the citizens. This is a bottom up approach for improving the overall health of the nation starting at district level. Starting with treatment of areaspecific diseases and infections is an effective way to ensure good health all over the nation.
\end{abstract}

CCS CONCEPTSApplied computing $\rightarrow$ Enterprise architecture frameworks

KEYWORDS:Public health access framework, egovernance, Health Improvement Index, Health Knowledge Centre (HKC)

\section{INTRODUCTION}

The growth of public health in India has been moderate due to low public expenditure on health, less public health institutes and insufficient national standards for public health education. As per the Global Burden of Disease Study (GBD) reported in The Lancet, India has a depressing $154^{\text {th }}$ place among 195 countries on the healthcare index. According to the study, India has performed below par in confronting cases of tuberculosis, diabetes, chronic kidney diseases and rheumatic heart diseases. The journal reports India among the biggest underachievers in Asia in healthcare access [1].

India has a huge population of 1.21 billion and occupies the second position as the most populous country in the world next to China. India encompasses almost 13.1 per cent of child population aged 0-6 years (Census 2011).

Revised Version Manuscript Received on 16 September, 2019.

* Correspondence Author

Kollapalli Ramesh Babu - Associate Professor, VidyaJyothi Institute of Technology, Aziz Nagar, Hyderabad, Telengana, krameshbabucse@vjit.ac.in A B Sagar - National Informatics Center, India sagar.phdcs@gmail.com AshishKataria - National Informatics Center, India ashishkatarias@gmail.com
Mortality among infants and under-5 youngsters is also a main concern. In India the number of Under-5 mortality rate and infant mortality rates are very high. The rates are nearly 49 and 42 respectively.

As per World Health Organization[WHO], health is defined as a "a state of complete physical, mental \& social well-being, and not merely an absence of disease or infirmity". Several indicators are used for the assessment of health which describe the population health status of a region. The key indicators of health are: Mortality, morbidity, disability rate, nutritional status, health care delivery, environmental, Socio-economic, others.

According to the WHO, Indian population is one of the most depressed countries in the world. While about $9 \%$ of individuals in the country admit they have experienced extended periods of depression at least once within their lifetime, nearly 36\% have suffered from Major Depressive Episodes (MDE) [4]. Support groups pool people facing similar issues, whether that's illness, relationship problems or major life changes. Participants of support groups often share experiences and advice. Research has established that it will be useful to be with other people who are in the same situation. Support groups moreover come in a variety of formats, including in person, on the Internet or by telephone. They could be run by professional facilitators - such as a nurse, social worker or psychologist - or by group members. Many support groups put emphasis on emotional support and shared experiences. There are numerous benefits of participating in support groups. Patients who join feel less lonely, isolated or judged, gain a sense of empowerment and control, develop coping skills and sense of adjustment, talk openly and honestly about their feelings, reduce distress, depression, anxiety or fatigue, develop a clearer understanding of what to expect with their situation, get practical recommendation or information about treatment options, compare notes about resources, such as doctors and alternative options, and etc. In other words, support groups could help greatly in improving access to good health. So, in our framework, we include the concept of connecting the patients with respective support groups as part of improving wellbeing of the patient [12]. The doctor-patient ratio in India is 1:2000 which is extremely lesser than the WHO-prescribed limit of 1:1000. India dropped to 36 doctors per hundred thousand population. The doctor scarcity was one of the health-management failures cited 


\section{A Rudimentary Framework for Improving Access to Public Health Using ICT}

by the report of a parliamentary committee on health and family welfare, which presented its findings on March 8, 2016.

\begin{tabular}{|l||r|r|r|}
\hline Country & IMR (per 1000 live births) Life Expectancy M/F (in years) MMR (per 100000 live births) & TFR \\
\hline India & $5863.9 / 66.9$ & 301 & 290 \\
\hline China & $3270.6 / 74.2$ & 56 & 172 \\
\hline Japan & $378.9 / 86.1$ & 10 & 135 \\
\hline Republic of Korea & $374.2 / 81.5$ & 20 & 119 \\
\hline Indonesia & $3666.2 / 69.9$ & 230 & 225 \\
\hline Malaysia & $971.6 / 76.2$ & 41 & 271 \\
\hline Vietnam & $2769.5 / 73.5$ & 130 & 219 \\
\hline Bangladesh & $5263.3 / 65.1$ & 380 & 304 \\
\hline Nepal & $5862.4 / 63.4$ & 740 & 340 \\
\hline Pakistan & $7364.0 / 64.3$ & 500 & 387 \\
\hline
\end{tabular}

Fig: 1 Health status of India compared to other countries

Public health IT systems in the country exist in silos. Majority of the programmes and even state health departments have their own IT solutions for program reporting requirements. Since all systems work in silos they do not contribute in integrated decision making. Thus, there is a lack of standardization in architecture, data standards, and disease and service codes [2].

Progress in public health and community-based interventions has been hampered by the lack of a comprehensive evaluation framework [9]. Public health is the societal approach to protecting and promoting health. Generally through social, rather than individual, actions, public health seeks to improve the well-being of communities [10]. In such a case, ICT can prove to be a boon for India. But poor people have restricted access to information and, therefore, have a low level of awareness resulting in lack of improvements in rural healthcare [11]. We propose the concept of Health Knowledge Centers (HKC's) at district level. HKC can significantly help people in providing general information to improve their health. It can provide basic information like drinking more water, going for a brisk walk, eat one extra fruit or vegetable a day to more complex information like daily exercises, yoga poses to stay fit and also alert patients to the dangers of sedentary lifestyles, smoking, and eating foods that are high in salt, sugar and fat content. Moreover, HKCs will stay updated about new Healthcare technology advances and can also help people in choosing treatments i.e. from traditional to modern.

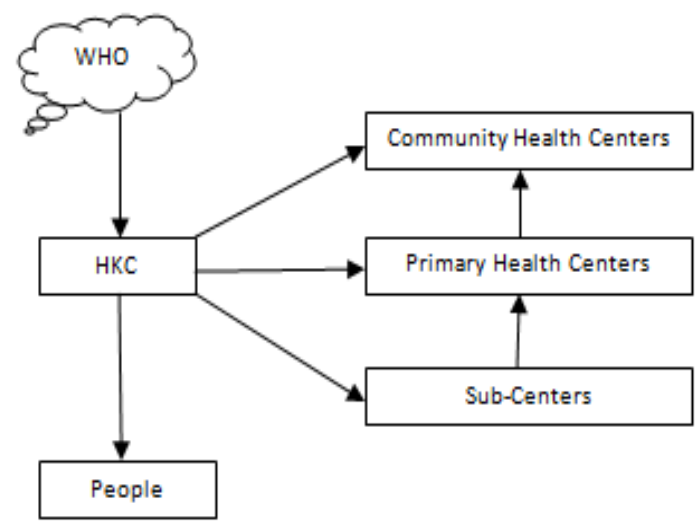

Fig 2: HKC Connectivity at district level

\section{PROPOSED FRAMEWORK}

The proposed framework is for improving the health of the citizens. This is a bottom up approach for improving the overall health of the nation starting at district level. Starting with treatment of area-specific diseases and infections is an effective way to ensure good health all over the nation. The proposed framework has three phases - 1. Research and Survey phase 2. Confirmation phase 3 . Treatment and Remedy phase

2.1 Research and Survey phase: In this phase, various medical personnel (lower level) will organize several public camps in the districts and meet the people, visit district and other government hospitals in the district and meet the doctors, and carry out a study on identifying the diseases prevalent in that district.

Software application has to be designed to store and organize all this data. No diagnosis or treatment is done in this phase.

2.2. Diagnosis \& Confirmation phase: In this phase, the data is confirmed for its validity by the expert doctors and specialists related to the diseases proposed in the phase 1 . Diagnoses may also be done in this phase for confirmation of the data. The software application has to properly link the diseases to the doctors and specialists and also arrange schedules for them to visit the sites.

2.3 Treatment phase: In this phase, actual remedial steps and treatment may be carried out. It is not possible to treat all cases at camps or local government hospitals. While some diseases related to skin, muscles, nerves, etc. may be treated immediately on site, other diseases related to cardiovascular, lungs, kidneys, etc. may need different hospitals as they require advanced equipment which cannot be deployed on site. In such cases, the patient may be referred to those hospitals. Due to high illiteracy rate in India, it is not in the common knowledge of many patients to know where the specialized hospitals are, or where their diseases can be treated best. There are many hospitals which are specialized for cancer, and some which are specialized for TB, heart, eyes, skin, etc. but most people are not aware of them. Social support is very essential during the remedy process.

There are a vast number of support groups for various issues such as depression, cancer, HIV, etc.

The experts will connect the patients with support groups. Also there are a number of NGOs willing to offer financial and other important services for free. So the experts could also refer to the NGOs if they find it suitable. Thus, even if the patient does not get immediate treatment, the patient will be able to get the knowledge about the possible places for treatment and a reference from the medical experts to the concerned specialized hospitals where he/she can avail best treatment.

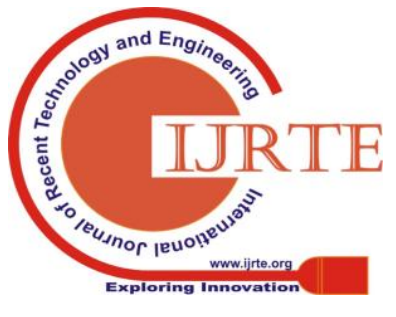


2.4 Feedback/Review phase: In this phase, patient satisfaction reviews will be taken and treatment effectiveness would be observed. Any suggestions or recommendations to be given or any issues to be reported to the district administration are also carried out in this phase. HKCs are given new information or suggestions as needed.Food and nutrition department plays an important role in our proposed framework. Several diseases and illnesses can be prevented and cured through consumption of balanced diet. The food and nutrition department surveys the district about the foods being consumed, foods being ignored, and creates a mapping between these and the diseases prevalent in the district. This mapping will be of great help for the district administration in improving the health status of the district. Several inferences can be drawn and several propositions can be made from the mapping. For example, if a district has a very high incidence of night blindness, and foods consumption survey shows a minimal intake of carrots - then a mapping can be drawn between less intake of carrots and high incidence of night blindness. Thus the district administration gets a point to focus on- improve awareness about consumption of carrots in diet and also direct agriculture department to take steps to ensure increase in carrots production in the district.

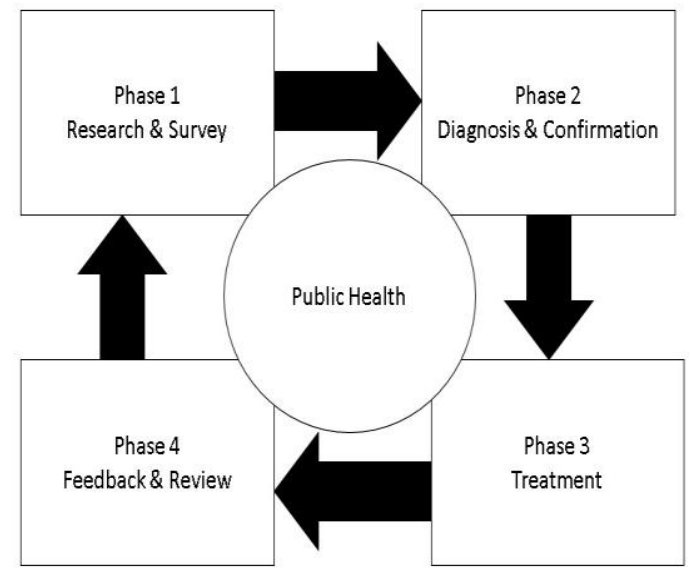

Fig 3: Basic Framework for Public Health

\section{IMPLEMENTATION}

In this section, we discuss the implementation of the proposed system through four phases.

\subsection{Phase 1 Implementation:}

The first module sorts the medical personnel data available in the database. It picks up personnel that are not engaged already and are of different medical departments and groups them into a team. Now each team comprises of personnel belonging to varied medical departments. The next module finds unvisited locations using the database. It uses the personnel data from the first module to find locations such that they are in close proximity to the personnel. The third module assigns the teams to various locations. The fourth module collects the research data provided by the medical personnel and stores it into the database.

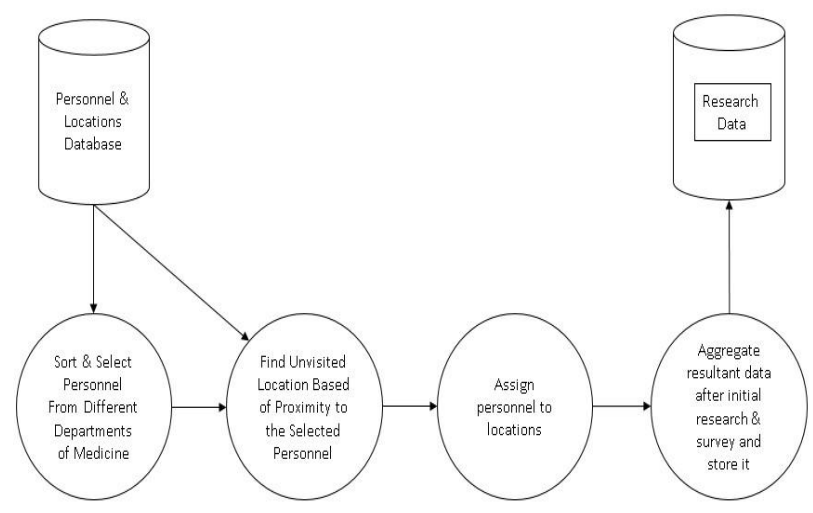

Fig 4: Phase 1 Implementation

\subsection{Phase 2 Implementation:}

The first module maps each and every finding of Research data of Phase 1 to a proposed database of expert doctors specialized in relevant diseases. At this point, each and every finding/disease of Research Data has an associated expert doctors specialized in that field. One doctor can be associated to multiple diseases. The second module records expert doctors' investigations on allocated disease and validates it and stores it into the database.

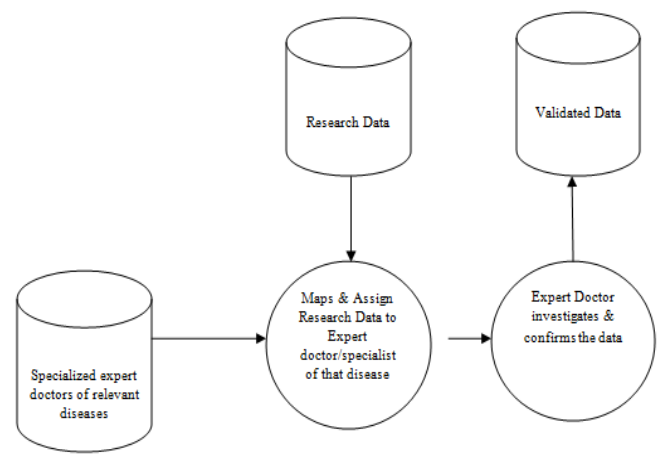

Fig 5: Phase 2 Implementation

\subsection{Phase 3 Implementation:}

After diagnosing a patient, if a doctor concludes that treatment can be done on site and treats the patient, then the module (Process Patient \& Treatment Details) will gather all the required data about the patient and the treatment and records the same in the Medical Records Database. It then passes the control to the module (Suggest corresponding Support Group or NGO) which accesses the 'Support Groups \& NGOs Database' and fetches corresponding needed data for the patient. In case the doctor decides that the patient cannot be treated on site, the module (Suggest Hospital \& Support Group/NGO) will access the 'Hospitals \& Specialty Centers Database' and fetches the corresponding data for the

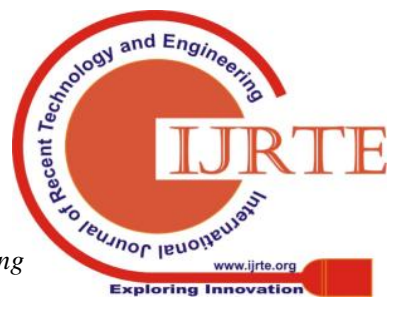




\section{A Rudimentary Framework for Improving Access to Public Health Using ICT}

patient. It also accesses 'Support Groups \& NGOs Database' and fetches information about the support groups or NGOs which could be of help to the patient. All these details are recorded in the Medical Records Database. In future, this data helps in identifying the diseases that are not being treated on site, and when an improvisation is planned, these cases can be considered and treatments for these diseases may be added.

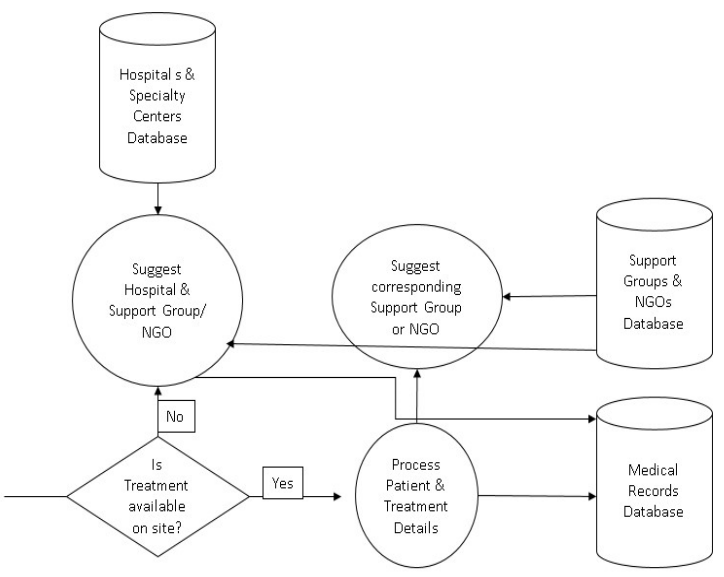

Fig 6: Phase 3 Implementation

\subsection{Phase 4 Implementation:}

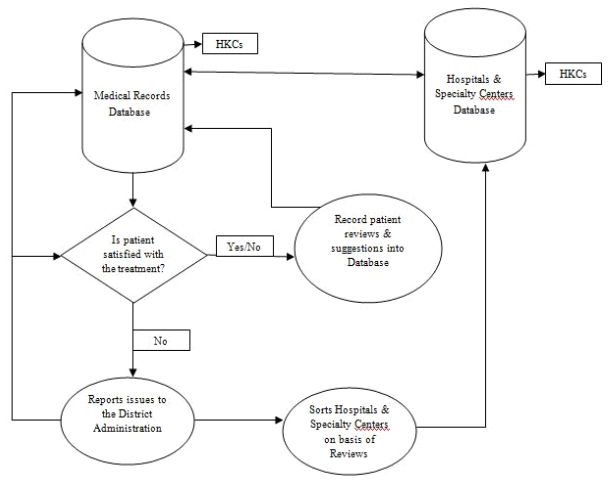

Fig 7: Phase 4 Implementation

Once the course of treatment is started, patient satisfaction with the treatment would be measured periodically in this phase. The patient is asked to provide feedback, reviews and suggestions about the given treatment. The module (Process patient reviews \& suggestions) will gather all the required inputs provided by the patient and records the same in the Medical Records Database. If patient was found to be satisfied with the ongoing treatment, the treatment continues. If patient was found dissatisfied with the ongoing treatment, the control passes to the module (Process Issues) which records and reports all issues to the District Administration department. The next module (Sorts Hospitals \& Specialty Centers) will do decision-making and sort all the Hospitals \& Specialty Centers on the basis of issues reported and reviews, feedbacks provided and records it to the Hospitals \& Specialty Centers Database which in turn pushes data to the Medical Records
Database. To improve the quality of treatment, it will pick up one of the next best ranking Hospital \& Specialty center from the Sorted list and assign it to the patient. HKCs are also having access to the Medical Records Database and Hospitals $\&$ Specialty centers Database.

\subsection{Software Implementation}

In this section we show some of the important screens that are used in the software.

Enter Support Group / NGO / Hospital Details :

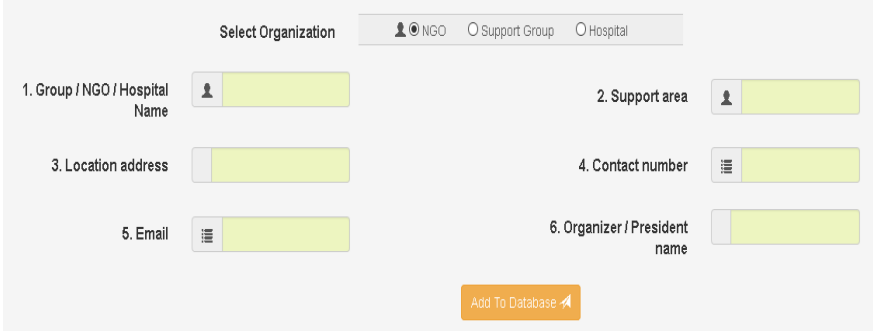

Fig 8: Screen for registration of support groups, NGOs or hospitals.

Enter Details::
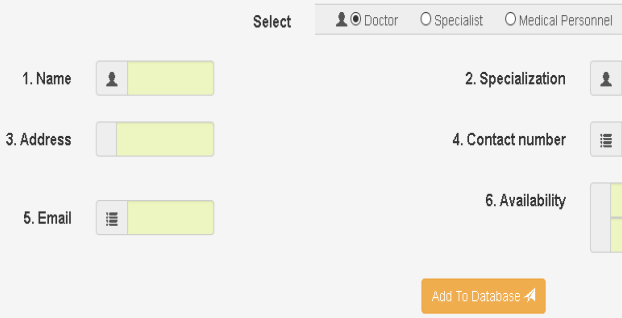

Fig 9: Screen for doctor, specialist or a medical personnel registration.

In the results, the nearest groups appear first and proceeding ones being farther away from the location of the medical camp site.

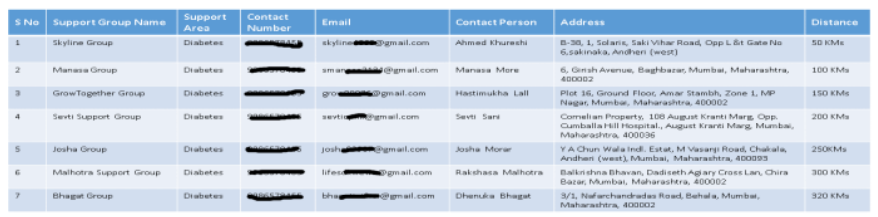

Fig 10: Screen showing results for doctor/specialist to refer a patient to a Support Group

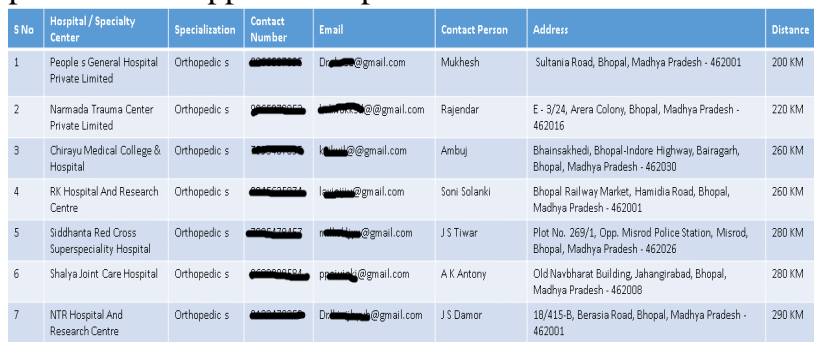

Fig11: Screen showing results for doctor/specialist to refer a patient to a different hospital or specialty center. 


\subsection{Health Improvement Index (HII)}

We propose a metric for measuring the performance of the proposed framework. The system is assumed to be working fine when all the patients that approach do get a successful treatment. It also implies that the medical personnel have done a good preliminary analysis and team formation has been successful to treat the patients properly and enough medical equipment is made available to the doctors to treat patients successfully. In case a patient has been diagnosed and referred to a different hospital, it implies that the proposed system has worked partially. The system has been able to choose doctors, specialists and medical personnel who could diagnose the case but were not able to treat it - may be due to complexity of the case or lack of medical devices on site. Hence we consider it as partial success only. In case a disease could not even be diagnosed, it implies a failure in the system in choosing medical personnel, doctors and specialists. This is a grave situation and has greater impact on the metric value. We compute the metric Health Improvement Index (HII) a given below. Here, 'd' refers to local administration area or a district.

Health Improvement Index, HII =

$$
\sum_{d=1}^{N}=\left[\frac{\left(\text { treated }_{d}\right)+\left(\text { referred }_{d} * 0.25\right) \text { - }\left(\text { NoTtreated }_{d} * 2\right)}{\text { Total }_{d}}\right]
$$

Here, 'treated $d_{d}$ ' refers to the total number of patients that are successfully treated in a district ' $d$ '. Patient satisfaction and doctor's input are considered while computing the value of 'treated' in the metric.

\section{Patient Satisfaction Scores:}

\begin{tabular}{|c|c|}
\hline Query & Score Value \\
\hline 1. Satisfaction & $(\operatorname{Min}-2, \operatorname{Max} 2)$ \\
\hline Very unsatisfied & -2 \\
\hline Unsatisfied & -1 \\
\hline Ordinary & $\mathbf{0}$ \\
\hline Satisfied & +1 \\
\hline Very satisfied & \\
\hline $\begin{array}{l}\text { 2. Were any delays in treatment or } \\
\text { services? }\end{array}$ & -1 or 1 \\
\hline Were there any delays in admission? & -1 or 1 \\
\hline $\begin{array}{l}\text { Patient given full, detailed, clear } \\
\text { explanations of tests, treatment } \\
\text { procedures }\end{array}$ & -1 or 1 \\
\hline Treatment plan explained completely & -1 or 1 \\
\hline Patient involvement in decisions & -1 or 1 \\
\hline $\begin{array}{l}\text { Greeting of patients and putting them } \\
\text { at ease }\end{array}$ & -1 or 1 \\
\hline Did you feel rushed by the doctor? & -1 or 1 \\
\hline $\begin{array}{l}\text { Experience of treatment making you } \\
\text { feel better }\end{array}$ & -1 or 1 \\
\hline $\begin{array}{l}\text { Experience at Hospital or Clinic } 10 \\
\text { pt. Scale }\end{array}$ & -1 or 1 \\
\hline
\end{tabular}

Table 1: Patient Satisfaction Scores

We have set a threshold value of 10 to assume a patient's satisfaction. If a patient scores a value above the threshold value, and the doctor also declares that the patient is successfully treated, then that patient will be counted under treated category, and the value of treated increments by 1 .

And, 'referred $d_{d}$ ' refers to the total number of patients in a district ' $d$ ' that are referred to other hospitals or speciality centers. And, 'NOTtreated ${ }_{d}$ 'refers to the total number of patients that are neither treated nor referred to other places. Total $_{d}$ refers to the total number of patients that have arrived for check up in the district ' $\mathrm{d}$ '. The best case will be when all the patients are treated successfully, then the HII value will be 1 . The worst case is when none of the patients are either treated or referred to other hospitals or speciality centers. In this case the value of HII will be -2 . And the average case value is -0.25 .

HII value always lies between -2 and 1 . Now we can see that as HII approaches positive number and increments towards to 1 , it can be considered positive and improving.

\section{RESULTS}

The project was launched as a pilot project in three districts of Madhya Pradesh: Alirajpur, Barwani and Jhabua districts. Volunteers have helped in the implementation of the project. The results were as below:

\begin{tabular}{|c|c|c|c|c|c|}
\hline $\begin{array}{c}\text { District } \\
\text { Name }\end{array}$ & $\begin{array}{c}\text { Treate } \\
\mathbf{d}\end{array}$ & Referred & $\begin{array}{c}\text { Not } \\
\text { Treate } \\
\mathbf{d}\end{array}$ & $\begin{array}{c}\text { Tot } \\
\text { al }\end{array}$ & HII \\
\hline Alirajpur & 320 & 150 & 0 & 470 & $\begin{array}{c}0.760 \\
6\end{array}$ \\
\hline Barwani & 405 & 115 & 0 & 520 & $\begin{array}{c}0.834 \\
1\end{array}$ \\
\hline Jhabua & 269 & 113 & 0 & 382 & $\begin{array}{c}0.778 \\
1\end{array}$ \\
\hline
\end{tabular}

\begin{tabular}{|c|c|c|l|l|l|}
\hline $\begin{array}{l}\text { Support } \\
\text { Groups }\end{array}$ & $\begin{array}{l}\text { NG } \\
\text { Os }\end{array}$ & $\begin{array}{l}\text { Hospita } \\
\text { ls / } \\
\text { Speciali } \\
\text { ty } \\
\text { Centers }\end{array}$ & $\begin{array}{l}\text { Medical } \\
\text { Personn } \\
\text { el } \\
\text { (Lower } \\
\text { Level) }\end{array}$ & $\begin{array}{l}\text { Docto } \\
\text { rs }\end{array}$ & $\begin{array}{l}\text { Speciali } \\
\text { sts }\end{array}$ \\
\hline 50 & 17 & 23 & 158 & 48 & 18 \\
\hline
\end{tabular}

\section{CONCLUSION \& FUTURE WORK}

The system has been very effective in its working. Since the doctors, specialists and medical personnel were computer literates, it has been easy to register them into the database. NGOs and Specialty Centers also got added with ease. Though some of the Support Groups had leaders who could not use a computer and Internet,

Published By: 


\section{A Rudimentary Framework for Improving Access to Public Health Using ICT}

there were other members in the support who did the registration. In future, a new feature has to be added through which patients themselves can add data to the survey. This makes the job of the medical personnel easy in creating the preliminary survey database. Several cases, though they were simple, were not treated due to lack of equipment and provision of medicines. A module has to be prepared to provide a requirement chart for the district administration so that they would have a clear idea on the equipment required and medicines to be kept in stock. Availability of funds is a major concern. As of now, only volunteers have been employed, but it is understood that good results can be obtained when there are dedicated paid staff. Less attendance of patients to the medical camp is due to lack of widespread publicity. Due to small number of attending patients, "not treated' cases were also zero. The 'not treated' cases may be high when the attended patients' number increases greatly and project is implemented in several locations. This is because, when project is implemented in several locations, the doctors and specialists allotment and diagnosis equipment scarcity issues arise.

\section{REFERENCES}

[1] Patricia S. Abril and Robert Plant. 2007. The patent holder's dilemma: Buy, sell, or troll? Commun. ACM 50, 1 (Jan. 2007), 36-44. DOI: http://dx.doi.org/10.1145/1188913.1188915

[2] I. F. Akyildiz, W. Su, Y. Sankarasubramaniam, and E. Cayirci. 2002. Wireless Sensor Networks: A Survey. Comm. ACM 38, 4 (2002), 393 422.

[3] David A. Anisi. 2003. Optimal Motion Control of a Ground Vehicle. Master's thesis. Royal Institute of Technology (KTH), Stockholm, Sweden.

[4] P. Bahl, R. Chancre, and J. Dungeon. 2004. SSCH: Slotted Seeded Channel Hopping for Capacity Improvement in IEEE 802.11 Ad-Hoc Wireless Networks. In Proceeding of the 10th International Conference on Mobile Computing and Networking (MobiCom'04). ACM, New York, NY, 112-117.

[5] Kenneth L. Clarkson. 1985. Algorithms for Closest-Point Problems (Computational Geometry). Ph.D. Dissertation. Stanford University, Palo Alto, CA. UMI Order Number: AAT 8506171.

[6] Jacques Cohen (Ed.). 1996. Special Issue: Digital Libraries. Commun. ACM 39, 11 (Nov. 1996).

[7] Bruce P. Douglass. 1998. Statecarts in use: structured analysis and object-orientation. In Lectures on Embedded Systems, Grzegorz Rozenberg and Frits W. Vaandrager (Eds.). Lecture Notes in Computer Science, Vol. 1494. Springer-Verlag, London, 368-394. DOI: http://dx.doi.org/10.1007/3-540-65193-429

[8] Ian Editor (Ed.). 2008. The title of book two (2nd. ed.). University of Chicago Press, Chicago, Chapter 100. DOI: http://dx.doi.org/10.1007/3540-09237-4

[9] E Glasgow, T M Vogt, S M Boles Am, Evaluating the public health impact of health promotion interventions: the RE-AIM framework J Public Health. 1999 Sep; 89(9): 1322-1327.

[10] Nancy E. Kass, "An Ethics Framework for Public Health", American Journal of Public Health 91, no. 11 (November 1, 2001): pp. 1776-1782. DOI: 10.2105/AJPH.91.11.1776

[11] Alok Deshpande et al., Application of internet of things in Healthcare sector for bottom of Pyramid in india, International Journal of Engineering Applied Sciences and Technology, 2016, Vol. 1, Issue 11, ISSN No. 2455-2143, Pages 28-33

[12] Promoting Health and Reducing Disparities in Populations, American Diabetes Association, Diabetes Care Jan 2017, 40 (Supplement 1) S6S10; DOI: $10.2337 / \mathrm{dc} 17-S 004$

\section{AUTHORS PROFILE}

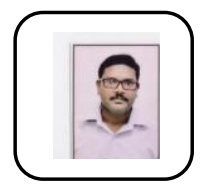

Dr.K.Ramesh babu , Associate Professor from CSE , Vidya Jyothi Institute of Technology. He has received $\mathrm{Ph} . \mathrm{D}$ from Central University, Hyderabad. $\mathrm{He}$ is a Life Member of CSI. His research interest areas are Computer Networks, Network Security, and Machine Learning

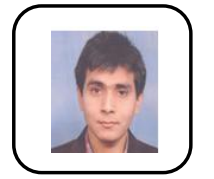

A B Sagar The author is an Informatics Officer in National Informatics Center. His research interests include micropayment schemes, ethics in information technology, web development, software engineering, etc. $\mathrm{He}$ has published several national and international journals and conferences

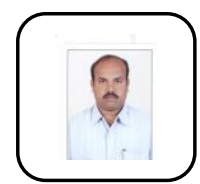

Ashish Kataria is a scientist in National Informatics Center. His main interests are micropayment schemes, ethics in information technology, web development, software engineering, etc. He has published several national and international journals and conferences. Applciation of information sciences for health is one of his main interests. 